\title{
Nyanyian Sasambo Sebagai Sarana Pendidikan Bagi Pemuda GMIST Jemaat Petra Manganitu
}

\author{
${ }^{1}$ David Onisius Damar, ${ }^{2}$ Alrik Lapian, ${ }^{3}$ Stefanny Mersiany Pandaleke
}

${ }^{1}$ Mahasiswa Program Studi Pendidikan Musik Gereja IAKN Manado, ${ }^{2}$ Dosen Program Studi Musik Gereja IAKN Manado, ${ }^{3}$ Dosen Program Studi Pendidikan Musik Gereja IAKN Manado

'bigdam777@gmail.com, ${ }^{1}$ alriklapian@yahoo.com, ${ }^{3}$ stefanny@iakn-manado.ac.id

\begin{abstract}
Abstrak
Penelitian ini merupakan kajian tentang nyanyian Sasambo sebagai sarana pendidikan bagi pemuda GMIST Jemaat Petra Manganitu. Sasambo dipahami sebagai sebutan nyanyian dalam bahasa Sangihe. Metode yang digunakan dalam penelitan ini adalah metode kualitatif dengan desain studi kasus. Teknik pengumpulan data dalam penelitian ini meliputi observasi, wawancara dan studi dokumen. Hasil penelitian menunjukkan bahwa nyanyian Sasambo ditinjau dari lirik dan aktivitasnya, dapat diimplementasikan sebagai sarana pendidikan bagi masyarakat Sangihe terlebih khusus bagi pemuda di GMIST Jemaat Petra Manganitu. Pendidikan yang dimaksud merupakan pendidikan non formal, yang menanamkan nilai, moral dan spiritual. Melalui nyanyian Sasambo, pemuda gereja diharapkan dapat menjadi teladan dalam pembentukan karakter dan pengembangan pendidikan di jemaat bagi generasi berikutnya.
\end{abstract}

Kata kunci: Nyanyian Sasambo, Sarana Pendidikan, Pemuda Gereja

\begin{abstract}
This research is a study of the Sasambo as a medium of education for the youth in the GMIST Petra Manganitu. Sasambo is understood as a singing term in Sangihe language. The method used in this research is a qualitative method with a case study design. Data collection techniques include observation, interviews and document study. The results showed that Sasambo, in terms of its lyric and activities, couled be implemented as a medium of education for the Sangihe community, especially for the youth in GMIST Petra Manganitu. The education is non formal education, which instills values, morals and spirituality. Through Sasambo, the church youth are expected to be role models in character building and educational development in the congregation for the next generation.
\end{abstract}

Keywords: Sasambo, Medium of Education, Church Youth 


\section{Pendahuluan}

Musik merupakan salah satu sarana yang digunakan untuk mencapai maksud dan tujuan pendidikan. Masyarakat Sangihe memiliki kekayaan musik sebagai bagian dari warisan para leluhurnya, diantaranya adalah nyanyian Sasambo. Nyanyian Sasambo merupakan nyanyian yang masih terpelihara oleh masyarakat Sangihe sampai saat ini. Sasambo berasal dari bahasa Sangihe, yakni Sasasa artinya pengajaran, dan Sambo artinya syair, mantra, kalimat petuah yang magis. Menurut Alvin Damar, masyarakat Sangihe umumnya memahami bahwa Sasambo telah dikenal dan dimengerti sebagai sebutan untuk nyanyian dalam bahasa Sangihe. ${ }^{1}$

Nyanyian Sasambo begitu unik dari isi maupun penyajiannya. Dari segi isi, nyanyian Sasambo memiliki syair-syair yang sarat akan nilai-nilai pendidikan. Syair nyanyian Sasambo berisi doa dan nasihat, nilai etik, moral dan spiritual, yang dijadikan sumber motivasi bagi masyarakat Sangihe untuk bertarung di tengah dinamika kehidupan yang terus berubah. Karena itu, nyanyian-nyanyian
Sasambo juga digunakan dalam liturgi beribadatan di gereja-gereja yang ada di wilayah Sangihe, khususnya di Gereja Masehi Injili di Sangihe Talaud (GMIST).

Berangkat dari hal tersebut, maka nyanyian Sasambo penting untuk digunakan dalam aktivitas jemaat gereja, terlebih kepada para pemuda gereja. Secara khusus bagi pemuda di GMIST Jemaat Petra Manganitu, nyanyian Sasambo dapat dijadikan sebagai sarana pendidikan untuk menanamkan nilai-nilai yang terkandung melalui syair dari nyanyian Sasambo, karena pemuda Jemaat Petra Manganitu belum secara optimal menggunakan serta melestarikan nyanyian Sasambo dalam peribadatan, khususnya ruang lingkup peribadatan pemuda gereja.

Berdasarkan uraian tersebut, maka peneliti berusaha untuk menjelaskan bahwa nyanyian Sasambo dapat digunakan sebagai sarana pendidikan bagi pemuda gereja, khususnya di GMIST Jemaat Petra Manganitu. Tujuan penelitian ini adalah menjelaskan dan mendekskripsikan nyanyian Sasambo yang digunakan sebagai sarana

\footnotetext{
${ }^{1}$ Alvin N. Damar, "Musik Tagonggong dan Sasambo Sebagai Sarana Penginjilan di Gereja Masili Injili Sangihe Talaud", Tesis, 2018, hlm. 128.
} 
pendidikan, yang ditinjau dari nilai-nilai dalam syair nyanyian Sasambo serta implementasinya.

Guna membingkai penelitian ini, maka pembahasan diuraikan berpijak pada beberapa konsep, antara lain musik etnik, yang dijelaskan oleh Perry Rumengan, yakni musik etnik merupakan musik yang lahir dari masyarakatnya sendiri, sehingga memiliki kekhasan atmosfirnya sendiri. Lebih lanjut lagi ditegaskan bahwa musik etnik memiliki elemen-elemen musikal yang khas, yang didasarkan pada falsafah, budaya dan perilaku masyarakatnya. $^{2}$

Sementara untuk konsep musik sebagai sarana pendidikan, berpijak dari konsep yang dijelaskan Banoe $^{3}$, yakni secara pedagogis sifat musik itu mendidik sehingga dapat memurnikan jiwa manusia. Sifat-sifat yang terbentuk dalam pendidikan musik bisa dilihat dalam nilainilai yang terbentuk pada pendidikan musik itu sendiri. Tujuan pendidikan musik merupakan upaya untuk mengembangkan dan membangkitkan minat dan rasa

\footnotetext{
2 Perry Rumengan, Musik Vokal Etnik Minahasa, (Jakarta:2009), hlm. 13.

${ }^{3}$ Pono Banoe, Metode Kelas Musik, (Jakarta: 2013), hlm.11.

${ }^{4}$ Ainoer Roffiq dkk, "Media Musik dan Lagu pada Proses Pembelajaran", Jurnal Pendidikan Dasar Indonesia, 2017, hlm. 38.
}

musikal kepada anak-anak. Lebih lanjut lagi ditegaskan oleh Roffiq $\mathrm{dkk}^{4}$, bahwa musik mempunyai pengaruh besar dalam kehidupan manusia, yakni dapat membawa manfaat untuk perkembangan kecerdasan otak yang memberi pengaruh pada aspek kognitif dan emosi. Sementara Pandaleke dan Panekenan dalam artikelnya mengungkapkan bahwa musik sebagai alat pendidikan berperan penting dalam pertumbuhan apresiasi dan kreativitas seseorang. Proses pendidikan musik bukan hanya terjadi pada lembaga pendidikan formal, tetapi juga terlaksana di ruang lingkup gereja. ${ }^{5}$

Kemudian peneliti juga menggunakan konsep yang berhubungan dengan nyanyian Sasambo, yakni Sasambo sebagai salah satu aset budaya masyarakat Sangihe yang harus dilestarikan. ${ }^{6}$ Hasil penelitian dari Maragani dan Wadiyo juga menunjukkan bahwa nilai-nilai yang tertanam pada masyarakat dalam kegiatan Masamper, terbentuk melalui proses interaksi yang terjadi pada saat kegiatan Masamper

\footnotetext{
5 Stefanny Mersiany Pandaleke \& Fian Panekenan, "Pendidikan Musik Sebagai Sarana Pengembangan Kreativitas Remaja Gereja Masehi Injili di Minahasa" Jurnal Clef: Musik dan Pendidikan Musik, Vol. 1 Nomor 1, 2020, hlm. 2.

${ }^{6}$ Elisabeth \& Bramantyo, "Musik Sasambo dalam Kebudayaan Masyarakat Sangihe dan Talaud", (Yogyakarta: 2004).
} 
berlangsung. ${ }^{7}$ Penelitian ini berkontribusi bagi peneliti sebagai bahasan musik etnik Sangihe, yang lebih dikhususkan pada nilai-nilai dalam Masamper.

\section{Metode}

Metode yang digunakan dalam penelitian ini adalah metode kualitatif dengan desain studi kasus. Penelitian kualitatif adalah penelitian yang bersifat deskripsi berupa ucapan, tulisan dan pengamatan. Lokasi penelitian bertempat di GMIST Jemaat Petra Manganitu, yang dimulai dengan tahap pra observasi pada bulan Desember 2019, kemudian penelitian dilanjutkan hingga bulan Juli 2020. Proses pengumpulan data yang dilakukan meliputi observasi, wawancara mendalam secara tatap muka dan online, serta studi dokumen. Teknik analisis data dimulai sejak pengumpulan data, reduksi data, penyajian hingga tahap verifikasi data.

\section{Hasil dan Pembahasan}

\section{Etimologi Sasambo}

Sasambo berasal dari bahasa Sangihe yakni dari kata Sasasa dan Sambo. Kata Sasasa berarti pengajaran, sedangkan kata Sambo berarti Syair. Bagi masyarakat Sangihe, Sasambo dipahami

\footnotetext{
7 Meytlsan Maragani \& Wadiyo, "Nilai-nilai yang Tertanam pada Masyarakat dalam Kegiatan Masamper di Desa Laonggo", Jurnal Catharsis, 2016, hlm. 52.
}

sebagai nyanyian dalam bahasa Sangihe. Dari asal usul kata bahkan dari pemahaman masyarakat Sangihe terhadap Sasambo, maka secara sederhana dapat dikatakan bahwa Sasambo adalah nyanyian yang berisi syair-syair pengajaran.

\section{Keberadaan Nyanyian Sasambo di Sangihe}

Nyanyian Sasambo merupakan kekayaan seni budaya masyarakat Sangihe yang diwariskan oleh para leluhur masyarakat Sangihe. Sebagaimana disebutkan oleh Nico Somboadile dalam tulisannya bahwa nyanyian Sasambo merupakan salah satu kekayaan musik suku Sangihe. ${ }^{8}$ Sebagai bagian dari kekayaan musik suku Sangihe, maka masyarakat Sangihe senantiasa menjaga kelestarian nyanyian Sasambo.

Nyanyian Sasambo telah menjadi bagian dari kehidupan masyarakat Sangihe dari zaman dahulu hingga sekarang ini. Keberadaan nyanyian Sasambo banyak dijumpai dalam kegiatan adat masyarakat Sangihe. Nyanyian Sasambo dengan iringan Tagonggong (sejenis alat musik perkusi) dipakai dalam kegiatan adat perkawinan masyarakat Sangihe.

Keberadaan nyanyian Sasambo lebih sering dijumpai dalam pelaksanaan

\footnotetext{
${ }^{8}$ Nico Somboadile, "Musik Masamper Di Sangihe Kontinuitas dan Perubahan Dalam Struktur dan Fungsi", Skripsi, 2008, hlm. 67.
} 
pesta adat Tulude. Pesta adat Tulude merupakan ritual adat pengucapan syukur masyarakat Sangihe kepada Tuhan sebagai pelindung dan pemelihara kehidupan manusia dan alam semesta yang dalam bahasa Sangihe dinamakan I Ghenggonalangi Duatang Saluruang. Nyanyian Sasambo juga banyak dimanfaatkan, dalam kegiatan-kegiatan kedaerahan seperti dalam penjemputan tamu-tamu, Sasambo berfungsi sebagai pengiring Tari Gunde,

Selain dalam kegiatan adat, sekarang ini nyanyian Sasambo juga telah dimanfaatkan dalam kegiatan ibadah di lingkungan Gereja Masehi Injili Sangihe Talaud (GMIST). Salah satu contohnya adalah dalam liturgi ibadah pembukaan Sidang Tahunan Sinode ke 3 Gereja Masehi Injili Sangihe Talaud yang dilaksanakan di kota Bitung tahun 2015.

\section{Bentuk dan Isi Sasambo}

Sasambo merupakan bagian dari kelompok Seni Sastra daerah Sangihe yang di dendangkan. Menurut Manatar, Sasambo juga terbagi dalam beberapa jenis yakni :

\section{Tatengkamohong \\ 2. Sambong Asi}

\footnotetext{
${ }^{9}$ Alvin N. Damar, "Musik Tagonggong dan Sasambo Sebagai Sarana Penginjilan di Gereja Masili Injili Sangihe Talaud", Tesis, 2018, hlm. 129 ${ }^{10} \mathrm{lbid}$

${ }^{11}$ Ambrosius Makasar, 10 Tema Budaya Kearifan Lokal Sumber Inspirasi Spiritual, Moral dan Etik Masyarakat Sangihe (Tahuna: 2009), hlm. 80.
}

\section{Sambong Salai}

4. Sambong Kihing Bango.

Pembagian jenis-jenis Sasambo sebagaimana yang dicatat di atas, sekaligus menjelaskan tentang konteks dimana Sasambo itu digunakan. ${ }^{9}$ Tatengkamohong adalah jenis Sasambo yang biasanya dipakai pada kegiatan upacara adat Tulude. $^{10}$ Sambong Asi, adalah jenis Sasambo yang digunakan oleh para petani di daerah kepulauan Sangihe pada saat membuka kebun baru untuk menanam padi.

Sasambo artinya nyanyian yang dilantunkan dengan diiringi alat musik tradisional Tagonggong (gendang), Su Pengasikang, di tempat saat dibukanya lahan untuk kebun baru. ${ }^{11}$ Dalam konteks ini, Sasambo yang dinyanyikan bersama iringan Tagonggong, berperan untuk memberi semangat kepada para petani saat bekerja untuk menanam padi di ladang, sekaligus sebagai doa kepada yang Maha Kuasa agar tanaman padi dapat bertumbuh dengan baik dan mendapatkan hasil panen yang melimpah. ${ }^{12}$

Sambong Salai adalah jenis Sasambo yang dipakai untuk mengiringi tari-tarian seperti tari Gunde. ${ }^{13}$ Untuk

\footnotetext{
${ }^{12}$ Alvin N. Damar, Musik Tagonggong dan Sasambo Sebagai Sarana Penginjilan di Gereja Masehi Injili Sangihe Talaud, h. 130.

${ }^{13}$ Alvin .N. Damar, "Struktur dan Fungsi Musik Tagonggong Dalam Tari Gunde", Skripsi, , 2009, hIm. 64.
} 
Sambong Salai menurut Manatar terdiri dari 4 (empat) jenis yakni : 1. Lagung Bawine, 2. Lagung Sasahola, 3. Lagung Sonda, 4. Lagung Balang. Sedangkan Sambong Kihing Bango adalah jenis Sasambo yang dipakai dalam kegiatan tradisi budaya masyarakat Sangihe yang disebut Kakalumpang. Kakalumpang adalah kegiatan mencukur kelapa sambil menyanyi yang dilakukan oleh banyak orang.

Dalam nyanyian Sasambo, ada yang dinyanyikan secara individu dan secara komunal. Dimana sampai sekarang, belum ada bentuk melodi yang tetap dari nyanyian ini dengan kata lain, bentuk melodi Sasambo dapat berubah-ubah setiap waktu, sekalipun itu untuk nyanyian Sasambo yang dibawakan secara individu maupun secara komunal. Hal ini disebabkan oleh karena penciptaan melodi Sasambo biasanya disesuaikan dengan keinginan dari penyanyi Sasambo itu sendiri. Melodi yang tercipta merupakan ungkapan dari gerak hati penyanyi Sasambo yang disesuaikan dengan penghayatan terhadap makna dari setiap syair Sasambo yang dinyanyikan. Jadi dalam hal ini, suasana hati serta kesungguhan penghayatan penyanyi terhadap makna syair sangat berpengaruh terhadap penciptaan melodi Sasambo, termasuk untuk penyajiannya. Keadaan ini juga mempengaruhi aksentuasi dan dinamika nyanyian Sasambo. Disamping itu, unsur aksentuasi dan dinamika juga dipengaruhi oleh aksentuasi serta emosi syair.

Menyangkut isi Sasambo dapat dimengerti melalui arti yang terkandung dalam setiap syair Sasambo. Ada lirik Sasambo yang berisi doa, harapan, pandangan hidup dan nasehat. Selanjutnya, dibawah ini akan diberikan beberapa contoh lirik dari Sasambo:

1. Sansahi Ghenggonalangi, Aking Su Endumang Sahi. Artinya: Nasihat Tuhan Allah, yakinkan di hati dengan sungguh.

2. Mamihetong Taghalroang, Abe $\mathrm{Pe}$ Biling Palrusang. Artinya: Bila menempuh lautan, jangan balik ke belakang.

3. Lumintu Dio Pe Kata, Abe Eno Kere Lana. Artinya: Jika keluar rumah harus beritahu, jangan mengalir seperti minyak.

4. Tuwo Ko Pengangendungang, Sombo $P e$ Sahintenoeng. Artinya: Bertumbuh jadilah contoh, hingga dewasa jadi panutan.

5. Bituing Ne Liku Bulrang, Naka Wantuge Daulru. Artinya: Bintang mengelilingi bulan, memberi kemuliaan bagi sang purnama.

\section{Pendidikan Melalui Nyanyian Sasambo} Sasambo bukanlah ungkapan biasa, melainkan sesuatu yang memiliki arti yang luas dan dalam. Disamping itu rumusan kalimat dalam lirik Sasambo, tidak diambil dari bahasa Sangihe yang biasa dipakai 
dalam komunikasi sehari-hari melainkan dari bahasa sastra daerah Sangihe yang secara struktur lebih tinggi tingkatannya dari bahasa tutur sehari-hari.

Oleh sebab itu, perlu dipaparkan arti dari nyanyian Sasambo. Sasambo yang bisa dijadikan sebagai sarana pendidikan serta, mengimplementasikan keberadaan nyanyian Sasambo sebagai sarana pendidikan bagi kehidupan masyarakat Sangihe pada umumnya dan secara khusus bagi para pemuda di GMIST Jemaat Petra Manganitu.

a. Sansahi Ghenggonalangi, aking su endumang sahi. Artinya: Nasihat Tuhan Allah, yakinkan di hati dengan sungguh. ${ }^{14}$ Masyarakat Sangihe dalam tatanan kehidupannya merupakan masyarakat yang religius. Hal ini dapat diamati melalui aktivitas keagamaan, dimana agama Kristen dan Islam merupakan kepercayaan yang dianut oleh masyarakat Sangihe. Sasambo sebagai nyanyian kepercayaan sering digunakan dalam peribadatan gereja, bahkan jauh sebelum masyarakat Sangihe mengenal agama, nyanyian Sasambo digunakan dalam kegiatankegiatan ritual adat masyarakat Sangihe.

b. Mamihetong Tagaloang, abe pe biling palusang. Artinya: Bila menempuh

\footnotetext{
14 Gidion Makamea, Mempelajari Ungkapan dan
} Sastra Daerah Sangihe I Kekendage, 2003. lautan, jangan balik ke belakang. Laut bagi masyarakat Sangihe bukan hanya sekedar tempat mencari nafkah, tetapi menjadi medan eksistensi kehidupan masyarakat di pulau Sangihe. Pembentukan jati diri kehidupan masyarakat yang mengasah keberanian, keuletan dan ketangguhan diri dalam menghadapi realitas serta dinamika kehidupan. Arti dari nyanyian ini mengungkapkan bahwa sebuah optimism kehidupan masyarakat Sangihe agar berani melangkah dalam meraih cita-cita kehidupan.

c. Tuwoko pengangendungang, sombo, pe sahintenoeng. Artinya: Bertumbuh jadilah contoh, hingga dewasa jadilah panutan. Keteldanan hidup merupakan salah satu bentuk pengajaran dalam lingkungan social dan budaya masyarakat Sangihe, baik dalam keluarga, sekolah, kegiatan adat maupun gereja. Arti nyanyian Sasambo ini diharapkan menjadi cermin evaluasi untuk melihat dan menata keberadaan diri, sehingga mampu menjadi pribadi berintegritas dan menjadi teladan.

d. Pali su kalenehang, tamai walang kahengang. Artinya: masih dalam keteduhan, dayunglah sungguh sungguh. Arti dari nyanyian ini menggambarkan rangkaian aktivitas 
masyarakat Sangihe sebagai nelayan. Bagi masyarakat nelayan, keteduhan lautan merupakan kesempatan terbaik untuk menjalankan aktivitasnya. Selain untuk mendapatkan ikan yang banyak, keteduhan lautan merupakan kesempatan untuk mendayung perahu bisa cepat sampai di pantai tujuan. Nyanyian ini mengajarkan bahwa setiap orang harus memanfaatkan waktu dengan baik dalam pekerjaan maupun dalam menikmati kehidupan alam ciptaan Tuhan.

e. Karima dame tumuwo, gighile taku I suang. Artinya: berharap kedamaian bertumbuh, kerukunan harus ku tanamkan. Kerukunan dalam nyanyian ini merupakan sebuah prasyarat bagi terciptanya sebuah kehidupan yang damai. Karena itu, nyanyian Sasambo ini telah menjadi nyanyian kehidupan yang terus menginspirasi masyarakat Sangihe demi terciptanya kehidupan yang penuh kedamaian. Untuk menciptakan kedamaian, bukan dengan menunggu orang lain melakukannya, melainkan harus dimulai dari diri sendiri.

\section{Nyanyian Sasambo Sebagai Sarana Pendidikan Bagi Pemuda GMIST Jemaat Petra Manganitu}

Dilihat dari segi pendidikan, nyanyian Sasambo memberikan arahan, sejarah, dan moral serta ada aspek pendidikan yang disampaikan melalui nyanyian yang dinyanyikan. Nyanyian Sasambo dapat menciptakan interaksi antar sesame anggota penyanyi Sasambo dengan penyanyi lainnya. Melalui interaksi tersebut, masyarakat saling memberi masukan dalam pencapaian yang lebih baik.

Implementasi nyanyian Sasambo sebagai sarana pendidikan, yang juga dijadikan sebagai bentuk pengajaran bagi pemuda GMIST Petra Manganitu. Sebagai wujud nyatanya, bisa terlihat dalam kegiatan ibadah melalui penggunaan nyanyian Sasambo di GMIST Jemaat Petra Manganitu. Orang-orang yang berpartisipasi aktif pada kegiatan tersebut akan menjadi sebuah kebiasaan yang baik bagi anggota pemudanya dan juga bisa menjadi teladan bagi generasi yang akan datang. Nyanyian Sasambo yang digunakan pada saat peribadatan di GMIST Petra Manganitu yaitu "Tatengkamohong" digunakan pada saat kegiatan adat Tulude. dan "Su Pengasikang" yang berarti sebagai doa atau permohonan kepada yang Maha Kuasa atas rasa syukur yang sudah dinyatakan.

Kegiatan dalam ibadah ini benarbenar suatu kesempatan bagi jemaatnya untuk menjadikan nyanyian Sasambo sebagai ruang untuk pemuda GMIST Petra Manganitu berkarya dalam sebuah kegiatan peribadatan. Musik dan peribadatan memang merupakan satu 
kesatuan yang tak terpisahkan, dimana hal ini memberikan kesempatan yang merata bagi jemaatnya untuk mempersiapkan, menata dan mengelolah peribadahannya dan pada akhirnya mengevaluasi kegiatan tersebut sehingga peranan nyanyian Sasambo dapat menunjang suasana peribadahan.

Berangkat dari hal tersebut, maka nyanyian Sasambo mempunyai keunikan bagi jemaat dan menjadi kekuatan untuk membangun suasana peribadatan, juga dapat digunakan dalam liturgi ibadah dan ini menjadi nilai yang baik untuk mencapai proses pendidikan bagi pemuda GMIST Petra Manganitu dalam membentuk karakter dalam penggunaan dan pengembangan nyanyian Sasambo di jemaatnya. GMIST Petra Manganitu yang memelihara nyanyian Sasambo pada setiap kegiatan, ini akan menjadi sebuah kebiasaan yang baik bagi anggota pemudanya dan juga bisa menjadi teladan bagi generasi yang akan datang.

\section{Kesimpulan}

Berdasarkan hasil penelitian yang dilakukan peneliti mengambil kesimpulan bahwa nyanyian Sasambo melalui lirik dan aktivitasnya dapat dijadikan sebagai media pendidikan. Ditinjau dari liriknya, nyanyian Sasambo mengandung nilai-nilai religius, kebersamaan, keberanian, kedamaian, ketangguhan dalam bermasyarakat. Sementara dari aktivitasnya, nyanyian ini bisa menciptakan sebuah interaksi antar sesame anggota jemaat sehingga bisa saling memberikan masukan dan arahan.

Nyanyian Sasambo diharapkan dapat digunakan dan dikembangkan dalam implementasinya pada peribadatan pemuda gereja, khususnya di GMIST Jemaat Petra Manganitu. Melalui Nyanyian Sasambo, pemuda gereja dapat menjadi teladan dalam pembentukan karakter dan pengembangan pendidikan di jemaat bagi generasi yang akan datang.

\section{Kepustakaan}

Banoe, Ponoe. 2003. Kamus Musik. Yogyakarta: Kanisius.

Musik. Jakarta: PT. Indeks.

Damar, Alvin.N. 2009. Struktur dan Fungsi Musik Tagonggong Dalam Tari Gunde. Skripsi Sebagai Syarat Memperoleh Gelar Sarjana Pendidikan. FBS UNIMA Tondano.

2018. Musik Tagonggong dan Sasambo Sebagai Sarana Penginjilan di Gereja Masili Injili Sangihe Talaud. Tesis Sebagai Syarat Untuk Mencapai Gelar Magister Teologi. Program Pascasarjana Teologi UKIT Tomohon.

Elisabeth, M.L. Bramantyo, T. 2004. Musik Sasambo Dalam Kebudayaan Masyarakat Sangihe dan Talaud :: Sebuah Kajian Musikologis. Perpustakaan Universitas Gadjah Mada Yogyakarta.

Hendriana, E. C., Jacobus, A. 2016. Implementasi Pendidikan Karakter di Sekolah Melalui Keteladanan dan 
Pembiasaan. Kalbar: Jurnal Pendidikan Dasar Indonesia.

Makamea, Gideon. 2003. Mempelajari Ungkapan dan Sastra Daerah Sangihe I Kekendage.

Makasar, Ambrosius. 2009.10 Tema Budaya, Kearifan Lokal Sumber Inspirasi Spiritual Moral Etik Masyarakat Sangihe.Tahuna:BPS GMIST Bidang Marturia.

Maragani, M., Wadiyo. 2016. "Nilai-nilai yang Tertanam pada Masyarakat dalam Kegiatan Masamper di Desa Laonggo". Jurnal Catharsis.

Pandaleke, Stefanny Mersiany., Panekenan, Fian. 2020. "Pendidikan Musik Sebagai Sarana Pengembangan Kreativitas Remaja Gereja Masehi Injili di Minahasa". Jurnal Clef: Musik dan Pendidikan Musik, Vol. 1 (1): 1-10.

Roffiq, A., Qiram, I., Rubiono, G. 2017. Media Musik dan Lagu Pada Proses Pembelajaran. Jawa Timur: Jurnal Pendidikan Dasar Indonesia.

Rumengan, Perry. 2009. Musik Gerejawi Kontekstual Etnik. Jakarta: Panitia Pelaksana Kongres Kebudayaan Minahasa.

2011. Musik Vokal Etnik

Minahasa: Teori, Gramatika dan Estetika. Yogyakarta: Program Pascasarjana ISI Yogyakarta.

Somboadile, Nico. 2008. Musik Masamper Di Sangihe Kontinuitas dan Perubahan Dalam Struktur dan Fungsi. Skripsi tidak diterbitkan. Program Studi Pendidikan Sendratasik, Jurusan Pendidikan Seni Rupa dan Kerajinan Fakultas Bahasa dan Seni UNIMA Tondano. 